\title{
Transtemporal Suprajugular Approach with Neck Dissection for Jugular Foramen Tumor Resection: Operative Video
}

\author{
Christina E. Sarris $^{1}$ Shawn M. Stevens ${ }^{1} \quad$ Kaith K. Almefty ${ }^{1}$ \\ ${ }^{1}$ Department of Neurosurgery, Barrow Neurological Institute, \\ Address for correspondence Kaith K. Almefty, MD, c/o Neuroscience \\ St. Joseph's Hospital and Medical Center, Phoenix, Arizona, \\ Publications; Barrow Neurological Institute, St. Joseph's Hospital and \\ United States \\ Medical Center, 350 West Thomas Road.; Phoenix, AZ 85013, \\ United States (e-mail: Neuropub@barrowneuro.org).
}

J Neurol Surg B 2021;82(suppl S1):S55-S56.

\begin{abstract}
Keywords

- endoscopic-assisted microsurgery

- jugular foramen

- solitary fibrous tumor

- transtemporal suprajugular approach

This video demonstrates the transmastoid suprajugular approach with neck dissection to a solitary fibrous tumor involving the jugular foramen and upper cervical region. This patient was a 39-year-old man who presented with dysphagia and cranial nerve (CN) XI and CN XII palsies. Imaging revealed a large homogenously enhancing lesion involving the jugular foramen and extending into the retropharyngeal space (-Fig. 1). Radiographic findings supported a diagnosis of jugular foramen schwannoma. After an initial period of observation, the tumor demonstrated significant growth, and the patient agreed to proceed with surgery. The suprajugular approach allowed for exposure and resection of the tumor without mobilization of the facial nerve. The patient had an excellent clinical outcome with House-Brackmann grade-1 facial function, safely tolerated a regular diet, had intact CN XI function, and had a stable CN XII palsy (-Fig. 2). Pathology findings identified the tumor as a hemangiopericytoma World Health Organization grade 1 (solitary fibrous tumor).

The link to the video can be found at: https://youtu.be/C4sPyHcLMA0.
\end{abstract}

Disclosures

None.

Financial Support

None.

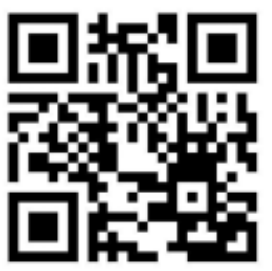

received

March 18, 2019

accepted

September 29, 2019

published online

March 13, 2020

www.thieme.com/skullbasevideos

www.thieme.com/jnlsbvideos

DOI https://doi.org/

10.1055/s-0040-1701680. ISSN 2193-6331.

\footnotetext{
(C) 2020. The Author(s).

This is an open access article published by Thieme under the terms of the Creative Commons Attribution-NonDerivative-NonCommercial-License, permitting copying and reproduction so long as the original work is given appropriate credit. Contents may not be used for commercial purposes, or adapted, remixed, transformed or built upon. (https://creativecommons.org/ licenses/by-nc-nd/4.0/) Georg Thieme Verlag KG, Rüdigerstraße 14, 70469 Stuttgart, Germany
} 


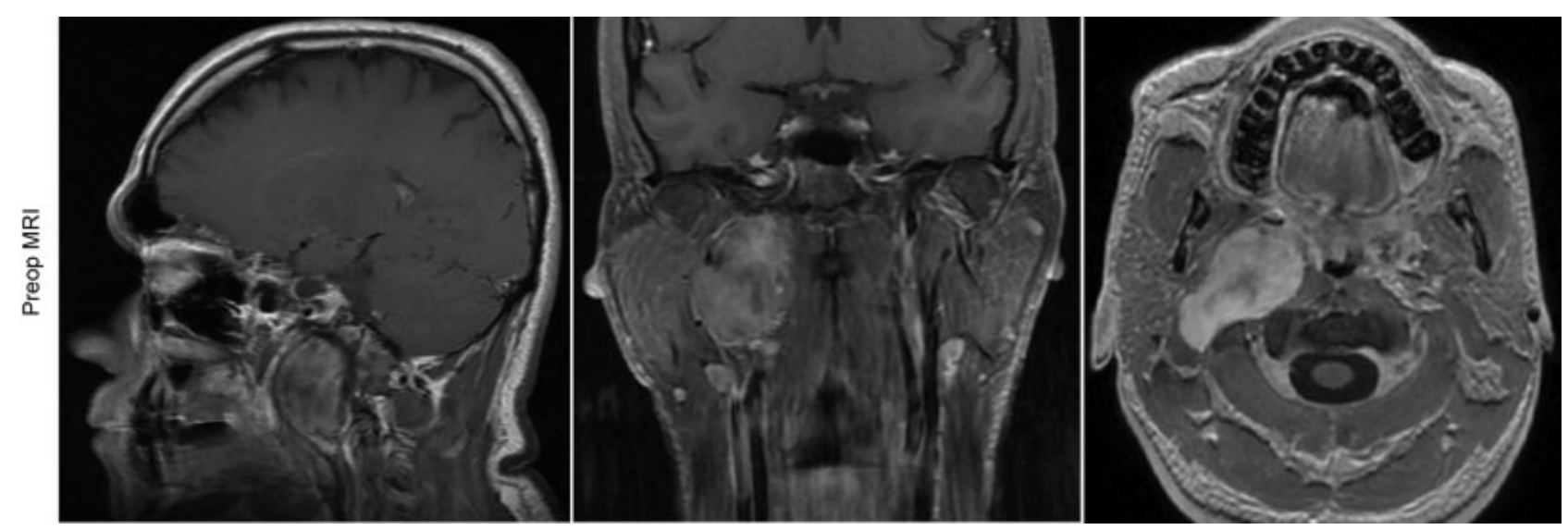

Fig. 1 Sagittal (left), coronal (middle), and axial (right) preoperative (Preop) magnetic resonance imaging (MRI) of a jugular foramen schwannoma. (Used with permission from Barrow Neurological Institute, Phoenix, Arizona.)
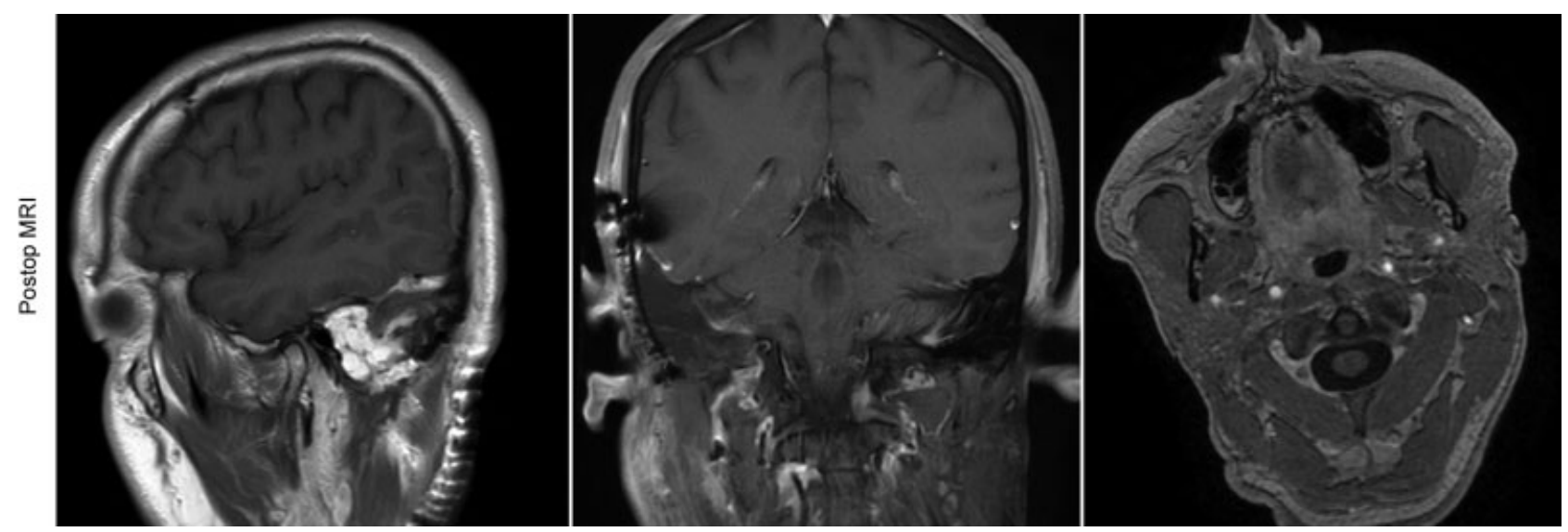

Fig. 2 Sagittal (left), coronal (middle), and axial (right) postoperative (Postop) magnetic resonance imaging (MRI) of a jugular foramen schwannoma. (Used with permission from Barrow Neurological Institute, Phoenix, Arizona.)

\section{Acknowledgment}

The authors thank the staff of Neuroscience Publications at Barrow Neurological Institute for assistance with manuscript and video preparation. 